\title{
Sensorial, Melissopalynological and Physico-Chemical Characteristics of Honey from Babors Kabylia's Region (Algeria)
}

\author{
Asma Ghorab 1,2,*(D), María Shantal Rodríguez-Flores ${ }^{2}\left(\mathbb{D}\right.$, Rifka Nakib ${ }^{2,3}{ }^{(0}$, Olga Escuredo $^{2}(\mathbb{D}$, \\ Latifa Haderbache ${ }^{4}$, Farid Bekdouche ${ }^{5}$ and María Carmen Seijo ${ }^{2, * \mathbb{D}}$ \\ 1 Laboratoire d'Ecologie et Environnement, Faculté des Sciences de la Nature et de la Vie, \\ Université A. Mira de Bejaia, Bejaia 06000, Algeria \\ 2 Department of Vegetal Biology and Soil Sciences, Facultade de Ciencias, \\ Universidade de Vigo, 32004 Ourense, Spain; mariasharodriguez@uvigo.es (M.S.R.-F.); \\ nakib.rifka@gmail.com (R.N.); oescuredo@uvigo.es (O.E.) \\ 3 Laboratory of Food Quality and Food Safety, University of Mouloud Mammeri, Tizi Ouzou 15000, Algeria \\ 4 Research Laboratory in Food Technology (LRTA), M'hamed Bougara University, Avenue de l'indépendance, \\ Boumerdes 35000, Algeria; 1.haderbache@univ-boumerdes.dz \\ 5 Department of Ecology and Environment, FSNV, University of Batna 2, Batna 05000, Algeria; \\ bekdouche_21@yahoo.fr \\ * Correspondence: asma.ghorab@uvigo.es (A.G.); mcoello@uvigo.es (M.C.S.)
}

check for updates

Citation: Ghorab, A.; RodríguezFlores, M.S.; Nakib, R.; Escuredo, O.; Haderbache, L.; Bekdouche, F.; Seijo, M.C. Sensorial, Melissopalynological and Physico-Chemical Characteristics of Honey from Babors Kabylia's Region (Algeria). Foods 2021, 10, 225. https://doi.org/10.3390/foods10020225

Academic Editor: Paweł Kafarski Received: 29 December 2020

Accepted: 19 January 2021

Published: 22 January 202

Publisher's Note: MDPI stays neutra with regard to jurisdictional claims in published maps and institutional affiliations.

Copyright: (c) 2021 by the authors. Licensee MDPI, Basel, Switzerland. This article is an open access article distributed under the terms and conditions of the Creative Commons Attribution (CC BY) license (https:// creativecommons.org/licenses/by/ $4.0 /)$

\begin{abstract}
This study aimed to characterize the honeys of Babors Kabylia through sensory, melissopalynological and physico-chemical parameters. Thirty samples of honey produced in this region were collected over a period of two years and analyzed. All the samples presented physico-chemical parameters in conformity with legislation on honey quality, with few exceptions, linked mainly to beekeeping management. The pollen spectrum revealed a great diversity with 96 pollen types. The main pollen types were spontaneous species as Fabaceae (Hedysarum, Trifolium, Genisteae plants), Asteraceae plants, Ericaceae (Erica arborea L.) or Myrtus and Pistacia. The sensory properties of samples showed a high tendency to crystallization, the colors were from white to brown, but most of them had gold color. Smell and odor corresponded mainly to vegetal and fruity families and in taste perceptions besides sweetness highlighted sourness and saltiness notes. Seventeen samples were polyfloral, one was from honeydew and twelve were monofloral from heather, genista plants, sulla, blackberry or Asteraceae. Heather and the honeydew samples showed the darkest color, the highest electrical conductivity and phenol and flavonoid content. A statistical analysis based on the most representative pollen types, sensory properties and some physico-chemical components allowed the differentiation of honey samples in terms of botanical origin.
\end{abstract}

Keywords: honey; Babors Kabylia; sensorial properties; melissopalynology; quality parameters; multivariate analysis

\section{Introduction}

Honey is one of the apian products more linked to the territory in which was produced, due to plant communities of the area, climate, soil and apicultural practices drive its characteristics. In Algeria, beekeeping is considered an integral part of the agricultural and rural routine. It is practiced in several regions but has been more important in the north of the country thanks to the appropriate climatic conditions and the great floristic biodiversity that provides honey resources during most of the year [1]. There are more than 20,000 beekeepers with 700,000 hives throughout Algeria, mainly are modern hives (Langstroth type and lesser Dadant type) and rarely are traditional hives. About $90 \%$ are independent and amateur and only $10 \%$ are professionals. 
Babors Kabylia's region is situated at the North east of Algeria being one of the most interesting regions for honey production in bio-geographical terms [2]. It has been considered as a biodiversity hotspot because of the richness of its flora and the presence of high number of endemic plants [3]. Within this large plant biodiversity, melliferous plants constitute an important part, so that it is possible to produce a wide variety of honey types [4-7]. According to [8,9], the plant species visited by the bees as well as the environment in which the honey was produced seem to have a strong influence on its quality and quantity; hence, it is possible to relate it to its geographical origin and on the other hand, honey could be a footprint of its environment.

The tellien sector of the Babors is made up of folded and scaled units. The soils are of a shisty and marly calcareous nature. Its Mediterranean-type climate is characterized by a rainy season mainly consisting of thunderstorms and torrential rains, concentrated during a very wet period from October to March with an average annual rainfall of nearly $900 \mathrm{~mm} /$ year, and a dry season between June and September. The vegetation is characterized by woodlands and shrubs, spontaneous plants, agricultural fields and other grasslands and hedgerows, forming a relatively heterogeneous landscape with numerous forage opportunities for honeybees.

The relief is from the sea level to high mountains (more than $1200 \mathrm{~m}$ ). At the north slopes of these mountains, the forest vegetation is very dense with woodlands of resinous species such as Cedrus atlantica (Endl.) Carrière and Abies numidica de Lannoy ex Carrière. and caducifolia oaks such as Quercus canariensis Willd. and Quercus afares Pomel. The southern slopes are practically devoid of forest vegetation being shrubs such as Calicotome spinosa (L.) Link. and some herbaceous plants as Ampelodesma mauritanicus (Poir.) Durand \& Schinz. At altitudes below $1200 \mathrm{~m}$, appear some degraded green oak forests (Quercus ilex L.), but is the domain of cork oak forest (Quercus suber L.), with firstly the humid facies of Cytisus villosus Pourr. and then, at lower altitudes, the thermophilic facies of Erica arborea L. Most of the beekeeping is practiced in this area. The maquis constitutes an interesting plant community for apiculture; more particularly Erica arborea and Pistacia lentiscus L. association, which covers the slopes located at less than $600 \mathrm{~m}$ of altitude in inland regions. It includes, among others, Cistus salviifolius L., Arbutus unedo L., Clinopodium vulgare L., Lavandula stoechas L., Daphne gnidium L. and Genista tricuspidata Desf. Its degradation also promotes a great biodiversity of spontaneous species characteristics of stripped soils: Cistus monspeliensis L., Bellis sylvestris Cirillo, Hypochaeris radicata L., Hedysarum coronarium L., Stachys ocymastrum (L.) Briq. and Poaceae as Ampelodesmos mauritanicus, Briza maxima L., Aira tenorei Guss., Festuca coerulescens Desf. or Cynosurus echinatus L. [10].

On the side of Draa El Kaid, between 500 and $700 \mathrm{~m}$ of altitude, close to the villages, grows a shrub with Retama sphaerocarpa (L.) Boiss., Calicotome spinosa, Thymus munbyanus subsp. ciliatus (Desf.) Greuter \& Burdet., Capparis spinose L., Ziziphus lotus (L.) Lam. and Teucrium polium L. On the North, the Gouraya National Park, have a vegetation characterized by a degraded shrub with Pinus halepensis Mill. dominated by Quercus coccifera L., Erica arborea, Erica multiflora L., Stachys ocymastrum and Glebionis coronaria (L.) Spach. [10]. Main agricultural crops are near to the coast and the rivers. The most common are Solanaceae as potatoes, tomatoes, peppers or Brassicaceae as cauliflower crops. Fruit arboriculture is represented by orchards of orange, lemon, apples and sometimes medlar. Deserving a special mention for viticulture are olives and fig trees.

Honey, the fruit of collaboration between the plant and animal worlds, has always been considered a sacred product because of its attributed nutritional and therapeutic benefits [11]. Furthermore, beekeeping is an environmentally friendly practice useful to promote local economy in areas with water scarcity and to facilitate pollination services in highly valued ecosystems. As occurs in many parts of the world, in Algeria, people prefer local beekeeping and consumers get their honey directly from beekeepers, trusting them for the quality and botanical origin of the honey. However, the characteristics of local productions are poorly studied and most Algerian honeys are mislabeled. In this context, increasing knowledge in local honeys contributes to their valorization and to avoid frauds 
for consumers. One of the main tasks is the authentication of the predominant botanical origin and quality. In this framework, sensory characteristics are the first attributes distinguished for consumers and together with melissopalynology deepen in the botanical and geographical origin of the honey [12]. Physico-chemical parameters complete the information to characterize local productions.

The objective of this study was to investigate the characteristics of the honey produced in one of declared Mediterranean biodiversity hotspots. For this purpose, thirty honey samples collected during the years 2018-2019, in the Babors Kabylia's region, a large geographical area of Northern Algeria, were analyzed.

\section{Materials and Methods}

\subsection{Study Area and Honey Samples}

The present study was conducted on 30 honey samples obtained from Apis mellifera intermissa apiaries situated throughout Babors Kabylia's region (North East of Algeria). The samples were collected during spring and summer seasons (2018-2019) and the honey extraction from the combs was by centrifugation (Table 1). Then the samples were stored in glass jars at $-4{ }^{\circ} \mathrm{C}$ until its analysis.

Table 1. Geographical origin of honey samples and period of harvest.

\begin{tabular}{cccc}
\hline Sample & Area & Harvest Period & Altitude (a.m.s.l.) \\
\hline M01 & Timsyet (Tizi N'berber) & Summer & 312 \\
M02 & Draa El-Gaid & Summer & 580 \\
M03 & Ighil Hassan & Summer & 320 \\
M04 & Lota village & Summer & 20 \\
M05 & Tahalaket (Tichy) & Summer & 167 \\
M06 & Ijouyaze Sahel & Summer & 205 \\
M07 & Adrar Oufarnou & Summer & 280 \\
M08 & Ait Aissa, Aokas & Summer & 185 \\
M09 & Djermana (Aokas) & Summer & 250 \\
M10 & Agwni Oukouche (Melbou) & Summer & 596 \\
M11 & Ouagaz Ichaabanen (Aokas) & Summer & 245 \\
M12 & Annar Assam & Summer & 335 \\
M13 & Annar Assam & Summer & 335 \\
M14 & Timsyet (Tizi N'berber) & Summer & 312 \\
M15 & Tahalaket & Spring & 167 \\
M16 & Tizi N'berber & Summer & 350 \\
M17 & Ouagaz Ichaabanen & Summer & 245 \\
M18 & Mechta Ledjbel (Ziama) & Summer & 590 \\
M19 & Draa El-Gaid & Summer & 580 \\
M20 & Tabelout & Summer & 305 \\
M21 & Tasabounet & Summer & 220 \\
M22 & Zentout-Tamrijet & Summer & 290 \\
M23 & Melbou & Summer & 03 \\
M24 & Ait Idir-Adekar & Summer & 500 \\
M25 & Tizi Ahmed & Summer & 330 \\
M26 & Agounane-Derguina & Summer & 300 \\
M27 & Djoa-Ajloh (Tichy) & Summer & 260 \\
M28 & AiT Anane-Derguina & Summer & 600 \\
M29 & Tababort & Summer & 280 \\
M30 & Boukhlifa & Summer & \\
\hline & & & \\
\hline
\end{tabular}

During the harvest season, the main melliferous plants of the region were identified and reference slides of pollen were prepared [13], for comparison with the pollen types found in the honey samples. 
The following determinations were carried out: sensorial analysis (color, smell, taste and aroma), melissopalynological analysis and physico-chemical analysis (quality parameters, phenol and flavonoid content and main mineral content).

\subsection{Sensorial Analysis}

Sensory analysis (visual, olfactory and gustatory characteristics) of collected honey samples was performed by a tasting panel constituted of a group of tasters (8 people) previously selected and trained according to international standards. The sensory test was performed in a sensory room under natural white light at room temperature. The samples were presented to the panel as $20 \mathrm{~mL}$ in small transparent glasses. Water was provided for rinsing the mouth between samples. Each honey sample was individually evaluated by descriptive grades using scales (1-10). The descriptors used for the evaluation can be seen in Table 2.

Table 2. Main descriptors used for sensorial analysis.

\begin{tabular}{cc}
\hline Sensory Perception & Descriptors \\
\hline Estate & Liquid, Crystallized \\
Color & White, Straw, Gold, Orange, Brown \\
Smell & Vegetal, Floral, Animal, Chemical, Fruity, Degraded \\
Taste & Sweetness, Bitterness, Saltiness, Sourness \\
Aroma & Vegetal, Floral, Animal, Chemical, Fruity, Degraded \\
Tertiary attributes & Astringency, Spicy \\
\hline
\end{tabular}

\subsection{Melissopalynological Analysis}

Pollen analysis was performed for quantitative results (number of pollen grains per gram of honey) and qualitative results (pollen spectra of the honey samples).

\subsubsection{Quantitative}

The methodology is based on the methods of melissopalynology [13]. Ten grams of honey were weighed and fully dissolved in $40 \mathrm{~mL}$ of warm distilled water (not above $40^{\circ} \mathrm{C}$ ). The solution was centrifuged for $10 \mathrm{~min}$ at $4500 \mathrm{rpm}$ and the supernatant was discarded. Afterwards, $40 \mathrm{~mL}$ of distilled water was added prior to centrifugation for $5 \mathrm{~min}$. The supernatant was again discarded until a volume of $5 \mathrm{~mL}$ and then the sediment was vortexed. For the microscopical analysis two drops $(10 \mu \mathrm{L})$ of this sediment were deposited in separate, over a slide. The total number of pollen grains in each drop were counted and the results were expressed as number of pollen grains per $\mathrm{g}$ of honey considering the mean value of both drops. Honeys are grouped considering the number of pollen grains per gram of honey (PG/G) into one of the following classes: Class I with less than 2000 pollen grains; Class II with 2000 to 10,000 pollen grains; Class III with 10,000 to 50,000 pollen grains; Class IV with between 50,000 and 100,000 pollen grains; and Class V with more than 100,000 pollen grains.

\subsubsection{Qualitative}

The obtained sediment for quantitative analysis was centrifuged again and the supernatant was discarded. After vortexing, two drops $(100 \mu \mathrm{L})$ of sediment were placed separately on a slide and distributed over an area of about $24 \times 24 \mathrm{~mm}$. Examination of pollen slides was performed using an optical microscope ( $400 \times$ or $1000 \times$, as appropriate). The percentage of representation for each type of pollen was calculated by counting at least 500 pollen grains per sample. The pollen grains were classified as pollen type, as genus or a single species, when it was possible. Following the recommendations suggested by [13], the pollen frequency classes were determined. 


\subsection{Physico-Chemical Analysis and Color Determination}

Quality parameters including honey freshness (HMF and diastase content), moisture, electrical conductivity, $\mathrm{pH}$ and free acidity were determined in duplicate and following methodologies proposed by the International Honey Commission [14].

\subsubsection{Honey Freshness}

HMF content was determined through the White spectrophotometric method. The absorbance of a honey solution was measured at 284 and $336 \mathrm{~nm}$ with a UV-visible spectrophotometer (Thermo Scientific Helios Gamma, Chorley, UK) against a blank. The determination of diastase activity was based on the quantity of starch converted by a honey solution and the absorbance of the resulting blue color. It was determined spectrophotometrically at $660 \mathrm{~nm}$ using a UV-visible spectrophotometer (Thermo Scientific Helios Gamma, Chorley, UK) at different times to an end point below 0.235. Diastase activity was expressed in diastase index (DI) Gothe Scale.

\subsubsection{Other Quality Parameters}

Water content was determined with a Carl-Zeiss Jena refractometer by measuring the refractive indices at $20^{\circ} \mathrm{C}$. The percentage of water was calculated using the CHATAWAY table. Electrical conductivity was performed at $20^{\circ} \mathrm{C}$ in a $20 \%(w / v)$ honey solution (dry matter basis) in $\mathrm{CO}_{2}$-free deionized distilled water using a portable conductivity meter (Knick Portamess ${ }^{\circledR} 913$ Conductivity, Beuckestr, Berlin, Germany). The values were expressed in $\mathrm{mS} / \mathrm{cm}$. pH was measured by a pHmeter (WTW inoLab pH 750) on a solution containing $10 \mathrm{~g}$ of honey dissolved in $75 \mathrm{~mL}$ of distilled water; the same solution was titrated for free acidity with $0.1 \mathrm{M}$ sodium hydroxide $(\mathrm{NaOH})$ solution up to a $\mathrm{pH}$ of 8.3. The results were expressed in $\mathrm{meq} / \mathrm{kg}$.

\subsubsection{Color of Honey}

Color determination was carried out using a HANNA Honey colorimeter (HANNA C221 Honey Color Analyzer, Rhode Island, RI, USA), previously calibrated with glycerin (Glycerol HANNA instruments, Rhode Island, RI, USA), which gives the values in millimeters Pfund.

\subsubsection{Polyphenol and Flavonoid Content}

The total phenolic content (TPC) was determined using an adapted Folin-Ciocalteu method [15]. Briefly, a honey solution for each sample was prepared $(0.1 \mathrm{~g} / \mathrm{mL})$ and mixed with $10 \mathrm{~mL}$ of distilled water, $1 \mathrm{~mL}$ of Folin-Ciocalteu reagent and $4 \mathrm{~mL}$ of $7.5 \%$ sodium carbonate $\left(\mathrm{Na}_{2} \mathrm{CO}_{3}\right)$ solution up to a final volume of $25 \mathrm{~mL}$. After incubation at room temperature in dark for $1 \mathrm{~h}$, the absorbance of the solution was measured by spectrophotometry at $765 \mathrm{~nm}$. Gallic acid (GA) was chosen as a standard, using various concentrated solutions $(0.01-0.50 \mathrm{mg} / \mathrm{mL})$, and then a calibration curve was obtained. The results were expressed as gallic acid equivalents in $\mathrm{mg} / 100 \mathrm{~g}$ of honey.

Total flavonoid content (TFC) was measured using an adaptation of the Dowd method [16]. The same first stock honey solution $(0.1 \mathrm{~g} / \mathrm{mL})$ prepared for the determination of phenol content was used. This solution was dissolved until a concentration of $0.33 \mathrm{~g} / \mathrm{mL}$ and $0.5 \mathrm{~mL}$ of $5 \%$ aluminum chloride $\left(\mathrm{AlCl}_{3}\right)$ solution was added prior to incubation in dark for $30 \mathrm{~min}$. The reaction yields a yellow color and their absorbance was determined spectrophotometrically at $425 \mathrm{~nm}$ after incubation in dark for $30 \mathrm{~min}$. The TFC was calculated using a calibration curve with different quercetin solutions $(0.002$ to $0.01 \mathrm{mg} / \mathrm{mL}$ ) and the results were expressed as mg equivalent of quercetin per $100 \mathrm{~g}$ of honey.

\subsubsection{Mineral Composition Analysis}

Mineral content of honey was quantified by inductively coupled plasma mass spectrometry (ICP-MS) and by Atomic Absorption spectrometry (AAS) using a Spectrometer 
Varian SpectraAA-600 (Agilent Technologies, Santa Clara, CA, USA). First, the samples were warmed and sonicated to facilitate the homogenization of honey, then $5 \mathrm{~mL}$ of $\mathrm{HNO}_{3}$ $\mathrm{H}_{2} \mathrm{O}_{2}$ 9:2 were added to $0.5 \mathrm{~g}$ aliquots of the homogenized honey and afterwards were digested in a microwave oven (CEM MARSX press model) [17]. ASS was used to determine $\mathrm{Na}, \mathrm{K}, \mathrm{Ca}, \mathrm{Mg}$ and $\mathrm{Fe}$ and ICP-MS for quantifying $\mathrm{Mn}, \mathrm{Cu}, \mathrm{Zn}, \mathrm{Cd}, \mathrm{Pb}$ and $\mathrm{P}$. The results were expressed as $\mathrm{mg}$ per $100 \mathrm{~g}$ of honey.

\subsection{Data Analysis}

Sensorial data was analyzed using the XLSTAT Sensory tool by Addinsoft (Paris, France). This package let to obtain the characterization of the samples considering the attributes perceived by the 8 tasters. The procedure for sample characterization and panel evaluation was used. Significant statistical differences were set as $p$-value $<0.05$. The radar charts for monofloral samples were done using the factorial values obtained in the characterization of products.

The package Analyzing data of XLSTAT was used as an exploratory statistical tool to reduce dimensionality of the multivariate data and to visualize them graphically, with minimal loss of information. PCA analysis was applied to identify groups of samples according to their botanical origin. This multivariate analysis allowed to summarize the information includes in the variables studied into a small number of principal components or factors providing a simplified interpretation of data variance through mathematical methods.

\section{Results and Discussion}

\subsection{Sensorial Profile of Samples}

Organoleptic properties are the first attributes that consumer can observed. These comprise visual properties as state, color, smell and aroma perceptions and taste. The descriptors considered in this work, to describe honey samples, had different discriminant power (Figure 1). The most useful were visual color, the different families of smell (animal, chemical, floral, fruity and vegetal), the persistence of smell, aroma perceptions (mainly fruity, vegetal, animal and floral families) and the saltiness for taste descriptors. The rest of the descriptors have been poorly detected so presented non-significant values.

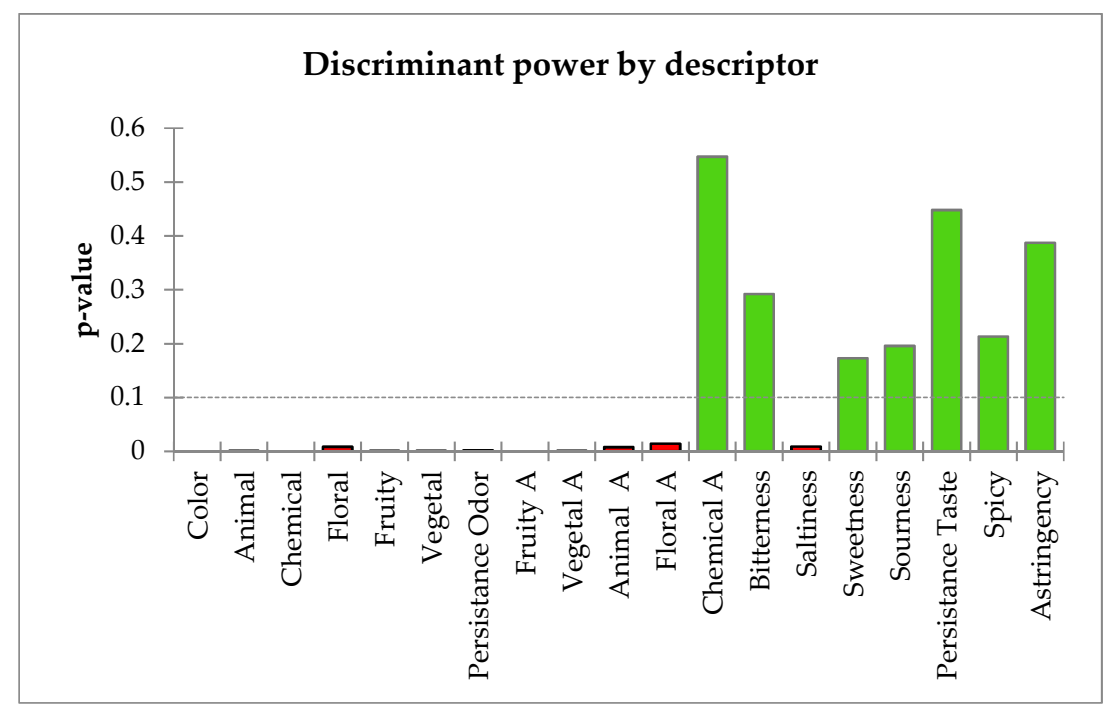

Figure 1. Sensorial descriptors used and their discriminant power.

All the samples were crystallized when the sensorial analysis was performed. Hence the scale used for color descriptors was from white to brown. The clearest samples were classified like straw color (two samples), 13 had gold color, five orange color and 10 brown color. The size of crystals was very fine or fine in 14 samples, medium in 15 samples while only one sample had large crystals. The tasters described the intensity of the smell as low 
being the predominant the vegetal in 21 samples, fruity in three and floral in two samples; however, secondary perceptions were mainly fruity, floral and in six samples, animal. The persistence of the odor was generally low or extremely low. Regarding the taste, besides the sweetness, tasters detected a degree of sourness and saltiness in most of the samples while bitterness was less common. When the aroma was considered, the most common perceptions were fruity, floral and in lesser extent vegetal. The most usual descriptors for vegetal smell or aroma were leaves, wood, mint, resin or cinnamon, for fruity were fresh fruit, tropical fruit, peach, dry grapes or fig, for floral were rose, lavender and violet and for animal leather and wax (except two samples in which tasters made associations with urine). Astringency was detected in a few samples. Finally, it should be mentioned that 15 samples had an intense smell to smoke (degraded family), that could be caused during the honey harvest. To protect quality beekeepers should improve honey management techniques.

\subsection{Pollen Spectra and Main Botanical Origin of Samples}

Ninety-six different pollen types were identified in the pollen spectrum of the honey samples including 77 nectariferous taxa and 19 taxa which do not produce nectar. Samples present a great diversity of pollen types, the mean value was 26 , but 12 samples had more than 30 different pollen types. The botanical families Fabaceae, Asteraceae, Apiaceae and Lamiaceae provide the $36.0 \%$ of the pollen types, standing out the diversity of Fabaceae plants which were $15.3 \%$ of identified types. Within this family, Genista and Hedysarum pollen types were the most frequent pollen grains. The first was present in $96.7 \%$ of the samples and the second one in $83.3 \%$ of them.

Genista was dominant pollen in three samples and the maximum value reached was $73.9 \%$ whereas Hedysarum was dominant pollen in two samples and had a maximum value of $63.2 \%$. For Asteraceae plants, Galactites t. was found in $70.0 \%$ but the values in the pollen spectra were lower than $7 \%$, while Aster t., identified in $50.0 \%$ of honeys, had a maximum value of $39.7 \%$. The most frequent Lamiaceae pollen was Stachys t., found in $70 \%$ of samples with a maximum value of $9.7 \%$. Other common pollen type was Thymus t. (46.7\% of samples) but values were always below 3\%. Finally, Apiaceae plants mainly as Foeniculum vulgare t. and Pimpinella anisum t. were found in $73.3 \%$ and $50.0 \%$ honeys, respectively (Table 3).

Table 3. Frequency classes of the main pollen types.

\begin{tabular}{|c|c|c|c|c|c|c|c|}
\hline Family & Pollen Type & $\begin{array}{l}\text { Max. } \\
(\%)\end{array}$ & $\begin{array}{c}D \\
(\geq 45 \%)\end{array}$ & $\begin{array}{c}A \\
(45-15 \%)\end{array}$ & $\begin{array}{c}R \\
(15-3 \%)\end{array}$ & $\begin{array}{c}I \\
(3-1 \%)\end{array}$ & Present ${ }^{1}$ \\
\hline Amaryllidaceae & Allium $\mathrm{t}$. & 5.7 & - & - & 1 & - & 11 \\
\hline Anacardiaceae & Pistacia & 30.0 & - & 2 & 7 & 4 & 22 \\
\hline Apiaceae & Daucus carota t. & 3.9 & - & - & 2 & 2 & 7 \\
\hline Apiaceae & Foeniculum vulgare t. & 9.0 & - & - & 5 & 6 & 22 \\
\hline Apiaceae & Pimpinella anisum $\mathrm{t}$. & 6.0 & - & - & 3 & 4 & 15 \\
\hline Asparagaceae & Asparagus acutifolius & 21.0 & - & 1 & - & - & 1 \\
\hline Asteraceae & Aster t. & 39.7 & - & 1 & 3 & 5 & 15 \\
\hline Asteraceae & Galactites t. & 6.9 & - & - & 3 & 3 & 21 \\
\hline Boraginaceae & Echium & 4.4 & - & - & 2 & 6 & 17 \\
\hline Capparaceae & Capparis spinosa & 12.7 & - & - & 1 & - & 4 \\
\hline Cistaceae & Cistus t. & 11.7 & - & - & 1 & 6 & 19 \\
\hline Cyperaceae & Carex & 5.0 & - & - & 1 & 2 & 6 \\
\hline Ericaceace & Erica & 72.8 & 4 & 7 & 7 & 4 & 25 \\
\hline Fabaceae & Astragalus & 22.1 & - & 1 & - & - & 1 \\
\hline Fabaceae & Ceratonia siliqua & 7.3 & - & - & 1 & 1 & 2 \\
\hline
\end{tabular}


Table 3. Cont.

\begin{tabular}{|c|c|c|c|c|c|c|c|}
\hline Family & Pollen Type & $\begin{array}{c}\text { Max. } \\
(\%)\end{array}$ & $\begin{array}{c}D \\
(\geq 45 \%)\end{array}$ & $\begin{array}{c}A \\
(45-15 \%)\end{array}$ & $\underset{(15-3 \%)}{R}$ & $\begin{array}{c}I \\
(3-1 \%)\end{array}$ & Present $^{1}$ \\
\hline Fabaceae & Genista $\mathrm{t}$ & 73.9 & 3 & 15 & 8 & 1 & 29 \\
\hline Fabaceae & Hedysarum & 63.2 & 1 & - & 7 & 6 & 20 \\
\hline Fabaceae & Lotus $\mathrm{t}$ & 7.3 & - & - & 4 & 5 & 21 \\
\hline Fabaceae & Spartium junceum t. & 16.8 & - & 1 & 5 & 1 & 8 \\
\hline Fabaceae & Trifolium repens t. & 17.9 & - & 1 & 10 & 4 & 26 \\
\hline Fagaceae & Castanea & 17.1 & - & 1 & 1 & - & 2 \\
\hline Fagaceae & Quercus & 7.6 & - & - & 2 & 2 & 12 \\
\hline Lamiaceae & Stachys t. & 9.7 & - & - & 6 & 7 & 21 \\
\hline Lythraceae & Punica granatum & 10.5 & - & - & 1 & 3 & 5 \\
\hline Myrtaceae & Eucalyptus & 41.9 & - & 2 & 4 & 4 & 16 \\
\hline Myrtaceae & Myrtus communis & 25.9 & - & 3 & 12 & 4 & 24 \\
\hline Oleaceae & Olea europaea & 6.1 & - & - & 1 & 1 & 4 \\
\hline Rosaceae & Crataegus t. & 7.1 & - & - & 4 & 2 & 8 \\
\hline Rosaceae & Prunus t. & 4.9 & - & - & 2 & 1 & 12 \\
\hline Rosaceae & Rubus & 58.7 & 1 & 1 & 3 & 7 & 21 \\
\hline Salicaceae & Salix & 11.6 & - & - & 4 & 1 & 11 \\
\hline Tamaricaceae & Tamarix & 5.7 & - & - & 1 & 1 & 4 \\
\hline
\end{tabular}

${ }^{1}$ Max.: maximum value reached by the pollen type in samples, D: number of samples in which the pollen type is dominant (percentage $\geq 45 \%$ ), A: number of samples where the pollen type is between $45 \%$ and $15 \%$, R: number of samples where the pollen type is between $15 \%$ and $3 \%$, I: number of samples where the pollen type is between $3 \%$ and 1\%, present: number of samples where the pollen type was identified. t.: pollen type common for different plant genera.

Despite the frequency of the mentioned botanical families in the honey samples, some other plants highlighted in the pollen spectra of honeys. The first was Erica genus, represented by the species E. arborea and E. multiflora. This pollen type was found in $70.0 \%$ of samples and had a maximum value of $72.8 \%$, being dominant pollen in four samples and secondary pollen in seven samples. In addition, Myrtaceae is well represented in the area due to the presence of Eucalyptus, used to reforestation, and Myrtus that grows in Mediterranean area commonly below $600 \mathrm{~m}$, both are present as secondary pollen in samples. Pistacia is other representative Mediterranean taxa, was present in $73.3 \%$ of honeys frequently with values under $15 \%$ but was secondary pollen in two samples. The area of study had an important rainy period that contributes to facilitate the introduction of some forest species in mountain areas as Castanea. The genus was only found in two samples, but its high bee value merit is to be considered. In the case of Rosaceae plants, the stand out, Rubus, presented in $70 \%$ of samples as being in one dominant pollen. Another mention should be made to the presence of Asparagus pollen, with a value of $21.0 \%$ in one sample.

The honey samples had medium pollen content in quantitative terms. Values ranged from 1117 to 23,196 grains/g, with an average of 6710 grains/g. Most of the samples $(66.7 \%)$ were classified in class II of Maurizio and $23.3 \%$ in class III. Only $10 \%$ of samples had low pollen content (Class I). This is according to the use of centrifugation to extract honeys from the combs.

\subsection{Quality Evaluation of the Honey Samples}

Overall, most of the honey samples showed acceptable quality parameters that were in accordance with the international legislation on honey quality [18].

The evaluation of the degree of freshness gave good results for most of the samples. $\mathrm{HMF}$ values were below the limit of $40 \mathrm{mg} / \mathrm{kg}$, having a mean value of $9.0 \mathrm{mg} / \mathrm{kg}$. The lowest value was $1.3 \mathrm{mg} / \mathrm{kg}$ and the highest value was $31.8 \mathrm{mg} / \mathrm{kg}$. Regarding diastase content, samples had extremely low values with a mean value of $11.3 \mathrm{DI}$. The minimum diastase level was 4.8 DI and the maximum was 29.0 DI. Ten honey samples had a diastase activity below $8 \mathrm{DI}$ (the minimum legal limit in international standards without considerations about HMF content). 
One important parameter for honey stability is water content. It varied from $16.4 \%$ to $19.8 \%$, with a mean value of $18.1 \%$. Most of the samples were collected during July and August and only one in April, but there were no differences in water content in relation to the date of harvest. Electrical conductivity was in general medium with a mean value of $0.60 \mathrm{mS} / \mathrm{cm}$, a minimum of $0.29 \mathrm{mS} / \mathrm{cm}$ and a maximum value of $1.35 \mathrm{mS} / \mathrm{cm}$. For $\mathrm{pH}$, the values oscillated from 3.5 to 4.4 with a mean value of 3.9. The values of electrical conductivity correspond mainly to blossom honeys; however, six samples presented values over $0.80 \mathrm{mS} / \mathrm{cm}$. Regarding to free acidity, all samples had values below the maximum permitted in European legislation which is 50 meq $/ \mathrm{kg}$ [18], ranging from $14.1 \mathrm{meq} / \mathrm{kg}$ to $46.5 \mathrm{meq} / \mathrm{kg}$ with a mean value of $32.4 \mathrm{meq} / \mathrm{kg}$. According to Pfund scale, the color of samples varied from extra light amber $(37 \mathrm{~mm})$, to dark amber $(135 \mathrm{~mm})$ with a mean value of $77 \mathrm{~mm}$. In addition to the differentiation between blossom honeys and honeydew honeys, the EC of honey is strongly related to its organic acids, ash content and proteins [19]. Therefore, the higher the content of the latter, the higher the obtained conductivity. A high content of organic acid and salts increases the free acidity present in honey.

\subsubsection{Mineral Content}

Considering the average value of samples, the most abundant minerals were $\mathrm{K}$ followed by $\mathrm{P}, \mathrm{Na}, \mathrm{Ca}$ and $\mathrm{Mg}$. The average value of $\mathrm{K}$ was $135.1 \mathrm{mg} / 100 \mathrm{~g}$ varying from a minimum of $43.1 \mathrm{mg} / 100 \mathrm{~g}$ to a maximum of $394.5 \mathrm{mg} / 100 \mathrm{~g}$. P varied from $17.6 \mathrm{mg} / 100 \mathrm{~g}$ to $36.6 \mathrm{mg} / 100 \mathrm{~g}$ and had an average of $25.8 \mathrm{mg} / 100 \mathrm{~g}$ and $\mathrm{Na}$, averaged $11.0 \mathrm{mg} / 100 \mathrm{~g}$ and ranged from 3.5 to $24.9 \mathrm{mg} / 100 \mathrm{~g}$. Ca and $\mathrm{Mg}$, had similar mean values of $7.5 \mathrm{mg} / 100 \mathrm{~g}$ and $5.5 \mathrm{mg} / 100 \mathrm{~g}$, respectively, whereas $\mathrm{Fe}, \mathrm{Mn}, \mathrm{Cu}, \mathrm{Zn}$, were found with the lowest values ranging from the maximum value of $1.2 \mathrm{mg} / 100 \mathrm{~g}$ for Fe in some samples to values lower than $0.2 \mathrm{mg} / 100 \mathrm{~g}$. $\mathrm{Cd}$ and $\mathrm{Pb}$ were always under the limit of detection. Normally, darker honeys had higher mineral content so heather honeys, chestnut honeys and honeydew honeys have the main values [20]. It has been proved by [21] that the botanical origin of honey has an impact on its elemental composition.

\subsubsection{Total Phenolic and Flavonoid Content}

The phenol content (TPC) and flavonoid content (TFC) are other interested parameters in honeys. TPC values ranged from $41.8 \mathrm{mg}$ GAE/100 $\mathrm{g}$ to $128.3 \mathrm{mg}$ GAE/100 $\mathrm{g}$, with a mean value of $70.6 \mathrm{mg}$ GAE/100 g, while TFC were in accordance with TPC and ranged from $2.3 \mathrm{mg}$ QE/100 to $9.7 \mathrm{mg} \mathrm{QE} / 100 \mathrm{~g}$, with a mean value of $4.9 \mathrm{mg} \mathrm{QE} / 100 \mathrm{~g}$.

These results were included within the interval found by [22] on honey samples from the same region and close to those reported by [23] on honeys from Algeria. Furthermore, TPC values were included in the range reported by [24] on Italian honey. Regarding TFC it is possible to find a great variation in values depending on the methodology used, but these values are higher than other reported from Moroccan honey [25] and Czech honey [26].

Both parameters are related with botanical origin of honey and hence with color, mineral content and electrical conductivity [20]. Previous studies have demonstrated a strong relationship between the phenolic profile of different honey types and their antioxidant capacities $[20,27,28]$. Therefore, further study of biological activities of honey produced in Babors Kabylia, such as the antioxidant power of honey samples, would be very interesting and necessary to show the correlation between the botanical origin and the content of phenolic compounds.

The most critical values for the quality of these samples correspond to water content and diastase index. All the analyzed samples presented a water content below the limit established by international legislation. However, values were higher than those reported for honeys from semiarid areas of Algeria [29]. Indeed, honeys produced in dry regions should have lower moisture content than honeys produced in humid regions. Similar values were reported by $[7,30]$ on honeys produced in a nearby region, as well as those produced in the Mediterranean coast [6], coinciding with the humid area of Algeria. In any cases, the studied samples had relatively high-water content that should be considered due 
to their relationship with stability and conservation of honey. Furthermore, high quality honeys should contain low HMF content and high Diastase index. Both parameters are thermosensitive and increase with aging and prolonged heating of honey [31]. Diastase content was frequently lower than the stablished limit in international legislation; however, HMF content does not exceed the limit. Similar values to those found in these sample was reported by [31] for Algerian honeys but higher values were also found [7]. It is essential to remark that water content and diastase index are dependent on several factors, including botanical and geographical origin, environmental and seasonal conditions, the degree of maturity and the beekeepers' handling during the honey harvest [32]. Studies on the common practices of honey management by beekeepers are necessary to determine the degree of influence on honey quality. In any case, the lack of professionalism combined with the quasi-total absence of training sessions related to beekeeping, hive maintenance, honey resources in the region and harvesting management, in addition to the propagation of Varroa disease and the absence of a legislative framework for quality recognition, can lead to problems linked to the quality of Algerian honey. In this context, to promote competitiveness with imported honey in the conventional market, it is recommended to promote knowledge of the characteristics of local honey and the participation of all stakeholders who can take actions to maintain the quality of the product.

\subsection{Multivariate Analysis Applied to the Interpretation of Samples Characteristics and Typification of the Honey Samples}

Data on the sensorial analysis, the main pollen types in the pollen spectra of samples and some physico-chemical parameters were used for PCA analysis. In total, 34 standardized variables were introduced to create the covariance matrix. The five first factors explained $92.0 \%$ of the variance of the data, and the first two $77.6 \%$. The first principal component (PC1) represented $62.3 \%$ of the variance and had the main correlation coefficients with the parameters of visual color (0.843), Pfund color (0.968), TPC (0.976), TFC (0.959), and Erica (0.856). The second one (15.2\% of the variance) had the highest positive correlation coefficient with Genista (0.936) and negative with Hedysarum (-0.733). Some of the variables are highly correlated and appeared together in the biplot (Figure 2a). At the right, sensorial perceptions such as vegetal odor and aroma, saltiness, bitterness and sourness taste and persistence of taste and smell, pollen types such as Erica or Pistacia and electrical conductivity, color, TPC, TFC and PH. At the left, are animal smell and sweetness taste together the pollen types Eucalyptus, Myrtus, Rubus, Aster and Hedysarum.

In the biplot of the two first components, the cases are dispersed but some similar samples appeared close (Figure $2 b$ ). At the right, it can be seen a group of samples with reference $\mathrm{H}$ (heather samples) and one Hd (honeydew sample). Up are the samples with the highest content in Genista pollen type and down, at the left, are the samples with the highest content of Hedysarum, Aster and the sample with Rubus as dominant pollen. In the center, there are a group of samples classified as polyfloral honeys $(\mathrm{P})$.

Analyzing the results, main taxa for honey production in this hotspot for biodiversity were Erica, Hedysarum, Genista plants and in lesser extent Myrtus, Eucalyptus and some Asteraceae plants. The importance of these plants for honey production was mentioned before by $[4,33,34]$. 


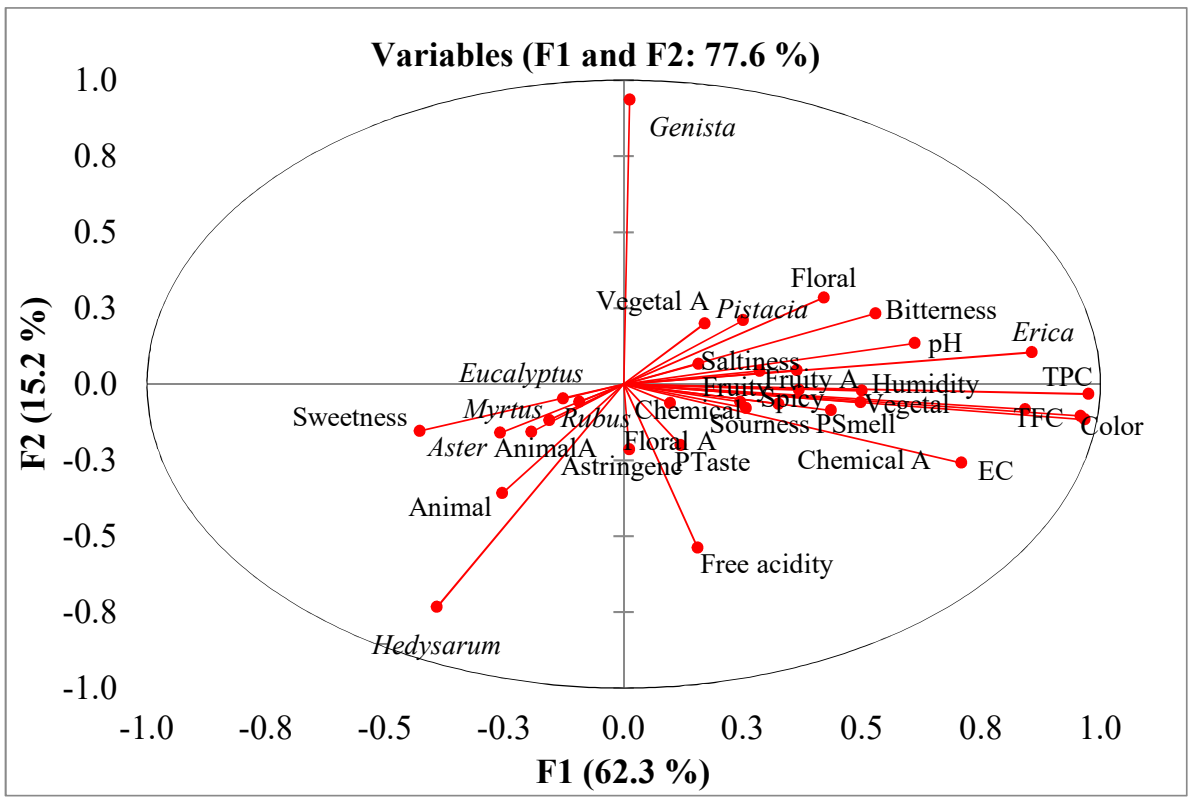

(a)

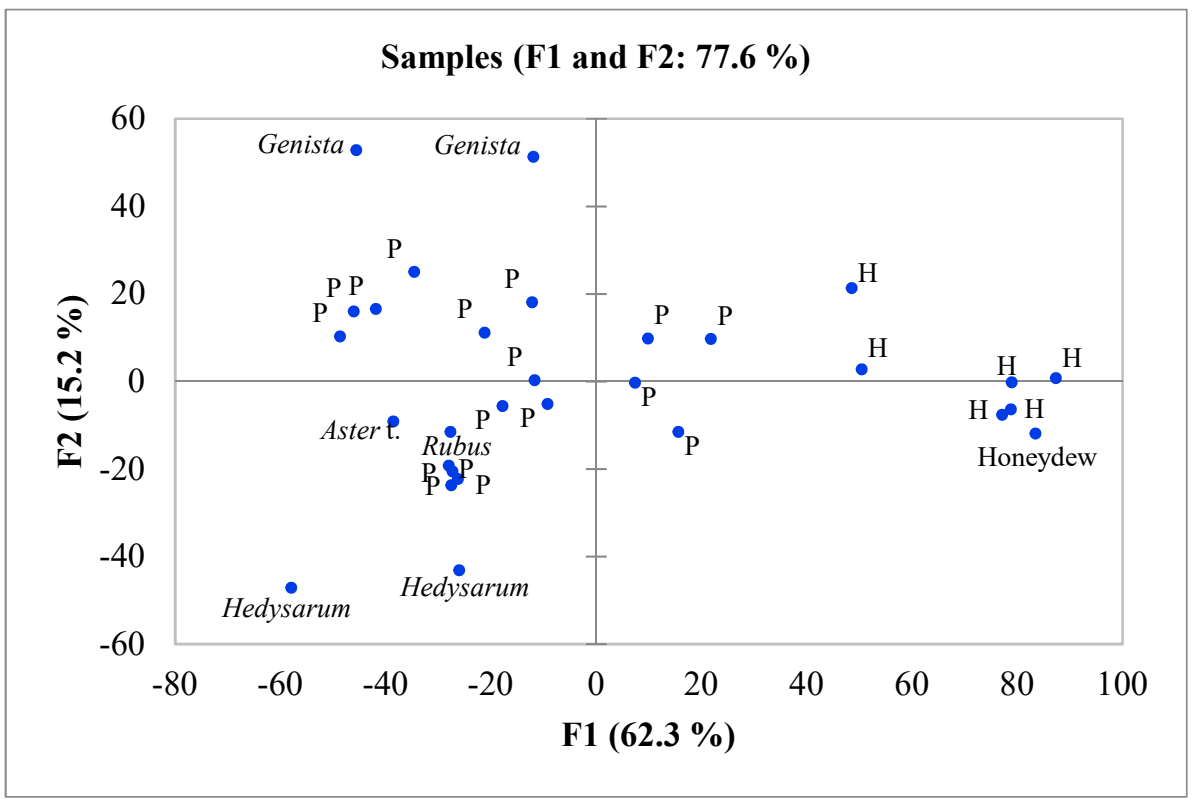

(b)

Figure 2. Principal Component Analysis (PCA). (a) Loading biplot of the variables included in the analysis, (b) Score biplot of the samples regarding component 1 and 2; P: Polyfloral, H: Heather.

The shrubs occupy a large surface in deforested areas and slopes of the mountains. These Mediterranean maquis has a great interest for apiculture, being the most representative species Erica arborea developing mainly on nutrient-poor acidic soils and Erica multiflora growing in calcareous soils. Both have been found in samples and give recognized and high valued unifloral honeys. Other plants such as Ceratonia siliqua L., Pistacia, Calicotome, Spartium junceum L., and Genista, and some Lamiaceae like Thymus or Lavandula, Phillyrea latifolia L. or different species of Cistus and Quercus form plant communities with Erica, so their pollen appears in honeys samples. It is worth mentioning the controversy on the apicultural value of Genisteae plants; while some species are considered that do not produce nectar (such as Calicotome spinosa), others are considered good nectariferous source for honeys such as Retama sphaerocarpa [35] or Spartocytisus supranubius (L.f.) Christ ex G. 
Kunkel [36]. In the case of some Genista species, Chamaecytisus and Retama nectar secretion was reported [37]. Furthermore, through the pollen spectra of samples, the great diversity in pollen types can be observed, and further, the high number of pollen types by sample in accordance with biodiversity of the area. In this sense, melissopalynology is a key analysis with which to identify geographical origin of honeys and to determine melliferous species in the area where honey has been collected [38].

Mainly, the apiaries were in altitudes lower than $600 \mathrm{~m}$ above sea level and near to villages. In these areas, shrubs and spontaneous plants are most common; therefore, they predominate in the pollen spectra of honeys. Spontaneous species have high melliferous yield; among them, standing out are the Fabaceae plants such as Hedysarum, which is represented in the area for some species [39], many species of Trifolium, Lotus and other as Securigera atlantica Boiss and Reut., Scorpiurus muricatus L., Tetragonolobus purpureus Moench, Astragalus echinatus Murray. and Medicago polymorpha L. The importance of Fabaceae for honey production in the region was mentioned previously, either to produce monofloral honeys and/or to participate importantly in the production of polyfloral honeys $[4,33,40-42]$. Their importance also appears in studies carried out on honeys from the Mediterranean regions of Algeria [2,7,34,43].

Other important herbaceous plants for honey yield were Lamiaceae and Asteraceae; both are the most visited after Fabaceae [44]. The best represented pollen type in samples belonging to the family Lamiaceae was Stachys, which includes plants like Stachys ocymastrum or Phlomis bovei Noë and many other plants of this family; these are probably exclusives of the area. Something similar occurs with Asteraceae plants; the best represented pollen type was Aster $\mathrm{t}$. with a pollen grain morphology similar for plants such as Aster, Helichrysum stoechas (L.) Moench, Dittrichia viscosa (L.) Greuter or Phagnalon saxatile (L.) Cass., frequently occurring plants in the area. Other pollen types of Asteraceae were identified in samples in lesser extents, but due to the possible contribution of these plants to honey production and the fact that they normally appear underrepresented in the pollen spectra of honeys [35], a deep investigation about vegetation and plant distribution in the area could help in the identification of honeybee resources.

\subsection{Characteristics of the Different Honey Types}

The interpretation of the data allowed us to classify 12 samples, such as unifloral six heather honeys, two sulla (Hedysarum) honeys, two Genista honeys, one blackberry (Rubus) honey, one Asteraceae honey), one like honeydew honey and the rest, as polyfloral.

Table 4 shows the mean and standard deviation values for physicochemical and main pollen parameters. Polyfloral honeys showed the highest variation between samples in most of the variables as correspond to the heterogeneity of the group. A great variation in pollen content within polyfloral samples was noted, ranging from class I, II and III, although some heather honeys, Hedysarum, Asteraceae and honeydew were found to be in class III. Regarding color, polyfloral honeys were mainly light amber, as found in Genista, Hedysarum, Asteraceae and Rubus honeys. However, honeydew and heather honeys were the darkest honeys. The honeys presented similar water content that ranged from 16.8 to $19.6 \%$. However, in terms of electrical conductivity and $\mathrm{pH}$, honeydew honey presented the highest values. At the other extremes were Genista honey with the lowest electrical conductivity and Rubus honey with the lowest $\mathrm{pH}$. 
Table 4. Values (mean and standard deviation) of the studied variables considering the botanical origin of samples.

\begin{tabular}{|c|c|c|c|c|c|c|c|}
\hline & $\begin{array}{l}\text { Asteraceae } \\
\quad(n=1)\end{array}$ & $\begin{array}{l}\text { Rubus } \\
(n=1)\end{array}$ & $\begin{array}{l}\text { Heather } \\
(n=6)\end{array}$ & $\begin{array}{l}\text { Sulla } \\
(n=2)\end{array}$ & $\begin{array}{c}\text { Genista } \\
(n=2)\end{array}$ & $\begin{array}{c}\text { Honeydew } \\
(n=1)\end{array}$ & $\begin{array}{l}\text { Polyfloral } \\
(n=17)\end{array}$ \\
\hline \multirow{2}{*}{ Main Pollen (\%) } & Aster $t$ & Rubus & Erica & Hedysarum & Genistat & & \\
\hline & 39.8 & 58.7 & $54.2 \pm 16.9$ & $58.8 \pm 6.2$ & $72.0 \pm 2.6$ & & \\
\hline PK (pollen/g) & 13686 & 5292 & $7248 \pm 4192$ & $11110 \pm 11338$ & $4174 \pm 2982$ & 14465 & $5118 \pm 5440$ \\
\hline Maurizio classes & III & II & II, III & III & II & III & I, II, III \\
\hline Humidity (\%) & 16.8 & 19.2 & $18.4 \pm 0.6$ & $18.1 \pm 2.4$ & $17.9 \pm 0.7$ & 19.6 & $17.9 \pm 1.0$ \\
\hline $\mathrm{EC}(\mathrm{mS} / \mathrm{cm})$ & 0.57 & 0.82 & $0.75 \pm 0.2$ & $0.54 \pm 0.3$ & $0.33 \pm 0.0$ & 1.35 & $0.55 \pm 0.2$ \\
\hline Free acidity & 33.5 & 35.5 & $34.7 \pm 10.2$ & $39.0 \pm 2.8$ & $15.5 \pm 0.7$ & 38.5 & $32.8 \pm 8.2$ \\
\hline \multirow{2}{*}{ Color (mm Pfund) } & 52 & 58 & $122 \pm 7$ & $53 \pm 23$ & $53 \pm 22$ & 135 & $66 \pm 17$ \\
\hline & Light Amber & Light Amber & Dark Amber & Light Amber & Light Amber & Dark Amber & Light Amber \\
\hline Diastase Index & 8.5 & 7.6 & $7.5 \pm 2.2$ & $14.8 \pm 2.8$ & $8.6 \pm 2.4$ & 16.9 & $12.5 \pm 5.9$ \\
\hline HMF (mg/100 g) & 10.3 & 10.5 & $4.9 \pm 0.8$ & $7.0 \pm 5.2$ & $4.1 \pm 0.5$ & 5.4 & $11.5 \pm 7.9$ \\
\hline Polyphenols (mg/100 g) & 49.6 & 53.9 & $109.8 \pm 16.4$ & $52.6 \pm 7.8$ & $52.6 \pm 11.2$ & 128.3 & $60.5 \pm 15.8$ \\
\hline Flavonoids (mg/100 g) & 3.3 & 3.6 & $7.9 \pm 1.3$ & $3.8 \pm 1.6$ & $3.2 \pm 1.3$ & 8.7 & $4.1 \pm 1.3$ \\
\hline $\mathrm{Na}(\mathrm{mg} / 100 \mathrm{~g})$ & 9.4 & 11.9 & $12.0 \pm 4.6$ & $9.1 \pm 5.1$ & $6.9 \pm 1.9$ & 9.8 & $11.5 \pm 5.9$ \\
\hline $\mathrm{K}(\mathrm{mg} / 100 \mathrm{~g})$ & 122.4 & 170.5 & $193 \pm 60.5$ & $105.5 \pm 71.4$ & $66.9 \pm 33.6$ & 394.4 & $109.5 \pm 55.7$ \\
\hline $\mathrm{Ca}(\mathrm{mg} / 100 \mathrm{~g})$ & 6.2 & 4.0 & $12.9 \pm 4.8$ & $6.2 \pm 3.2$ & $2.9 \pm 0.7$ & 14.7 & $6.1 \pm 1.6$ \\
\hline $\mathrm{Mg}(\mathrm{mg} / 100 \mathrm{~g})$ & 2.1 & 2.9 & $10.7 \pm 3.5$ & $2.7 \pm 1.7$ & $2.9 \pm 1.8$ & 11.2 & $4.3 \pm 2.6$ \\
\hline $\mathrm{Fe}(\mathrm{mg} / 100 \mathrm{~g})$ & 0.2 & 0.1 & $0.3 \pm 0.2$ & $0.3 \pm 0.1$ & $0.15 \pm 0.1$ & 1.3 & $0.15 \pm 0.1$ \\
\hline $\mathrm{Mn}(\mathrm{mg} / 100 \mathrm{~g})$ & $<0.2$ & $<0.2$ & $<0.35$ & $<0.2$ & $<0.2$ & 0.4 & $<0.2$ \\
\hline $\mathrm{Cu}(\mathrm{mg} / 100 \mathrm{~g})$ & $<0.2$ & $<0.2$ & $<0.2$ & $<0.2$ & $<0.2$ & $<0.2$ & $<0.2$ \\
\hline $\mathrm{Zn}(\mathrm{mg} / 100 \mathrm{~g})$ & 0.1 & 0.1 & $0.1 \pm 0.1$ & $0.1 \pm 0.0$ & $0.1 \pm 0.0$ & 0.1 & $0.1 \pm 0.1$ \\
\hline $\mathrm{Cd}(\mathrm{mg} / 100 \mathrm{~g})$ & $<0.1$ & $<0.1$ & $<0.1$ & $<0.1$ & $<0.1$ & $<0.1$ & $<0.1$ \\
\hline $\mathrm{Pb}(\mathrm{mg} / 100 \mathrm{~g})$ & $<0.1$ & $<0.1$ & $<0.1$ & $<0.1$ & $<0.1$ & $<0.1$ & $<0.1$ \\
\hline
\end{tabular}


Although Genista honeys had the lowest free acidity, all honey types had similar values. The same occurred with the HMF content. Honeydew honey had the highest average value of diastase index, while the lowest level was observed in heather honeys. This difference could be explained by the fact that the concentration of diastase depends on several factors, including handling conditions, and could not be a reliable indicator of the honey's origin. It could therefore be explained by the fact that the honeys may have been heated or improperly stored. The TPC and TFC also varied depending on the type of honey. Honeydew honey followed by heather honeys had the higher values of these compounds. Finally, the mineral content was higher in honeydew honey. Secondly, the high content of $\mathrm{K}, \mathrm{Ca}, \mathrm{Mg}$ and $\mathrm{Fe}$ in heather honeys were noteworthy. However, followed by Honeydew honey, the P content was higher in Asteraceae and Hedysarum honeys. Rubus honey type showed a light amber color but also a low TPC and TFC, although this type of honey showed a wide variation in color and varied from extra light amber to dark amber [45]. It is therefore necessary to study more Rubus honeys from this region to verify this finding.

The sensorial profile of the different honey types can be seen in Figure 3. The six samples of heather honey presented a common pattern with dark color (brown), when crystallized, predominant vegetal smell (leaves and resin), some floral features and fruity (dry and tropical fruit). The persistence of the smell was low whereas the persistence of the taste was medium, and samples presented saltiness, bitterness and sourness in similar intensity. The aroma was mainly fruity and vegetal. The Genista samples had similar pattern in smell and aroma but different color, one had straw color and the other orange color (both were crystallized). The smell was mainly floral and in lesser extent fruity and aroma was mainly fruity. The persistence of smell was low, and the persistence of the taste was medium, the intensity of the sweetness was high and presented some saltiness and sourness notes. Sulla honeys were the most different regarding their sensorial profile, one was darker than the other and the smell and the aroma of one of them was animal (leather) while the other had floral and fruity smell. The persistence of the smell and the taste were similar in both cases. Asteraceae samples presented orange color, fruity smell and aroma with low intensity and persistence for smell, aroma and taste. Regarding the blackberry honey, highlighted the floral and fruity smell and the fruity aroma as well as the predominance of sweetness in taste. Finally, the honeydew sample had brown color, vegetal odor, fruity aroma and the highest persistence of smell.

The published scientific information about sensory profile of honey is scarce $[12,35,46,47]$ and no information is available about sensorial properties of honey produced in Algerian country. The heather honeys were the most known and have similar sensorial profile to those previously described $[35,48]$. Regarding the sulla honeys were mainly described with floral smell but these samples were different in the smell having one of them fruity smell and the other animal smell, both with very low intensity [49]. Finally, the sensorial properties of Genista honeys are poorly described in literature, but its sensorial properties are near to other honey obtained from Fabaceae plants as Spartocytisus supranubius [36]. Other honey types are poorly known regarding their sensorial properties.

This is the first study focuses on the sensory properties of honey and their relationships with the botanical origin and the physicochemical properties of honeys from Babors Kabylia Region. Considering that this area is a hotspot for biodiversity and have a high potential for honey production, further studies could contribute to increase knowledge in the characteristics of the honey, the types that can be obtained and the most relevant plant species for honey yield and definitely contribute to the valorization of local beekeeping. 

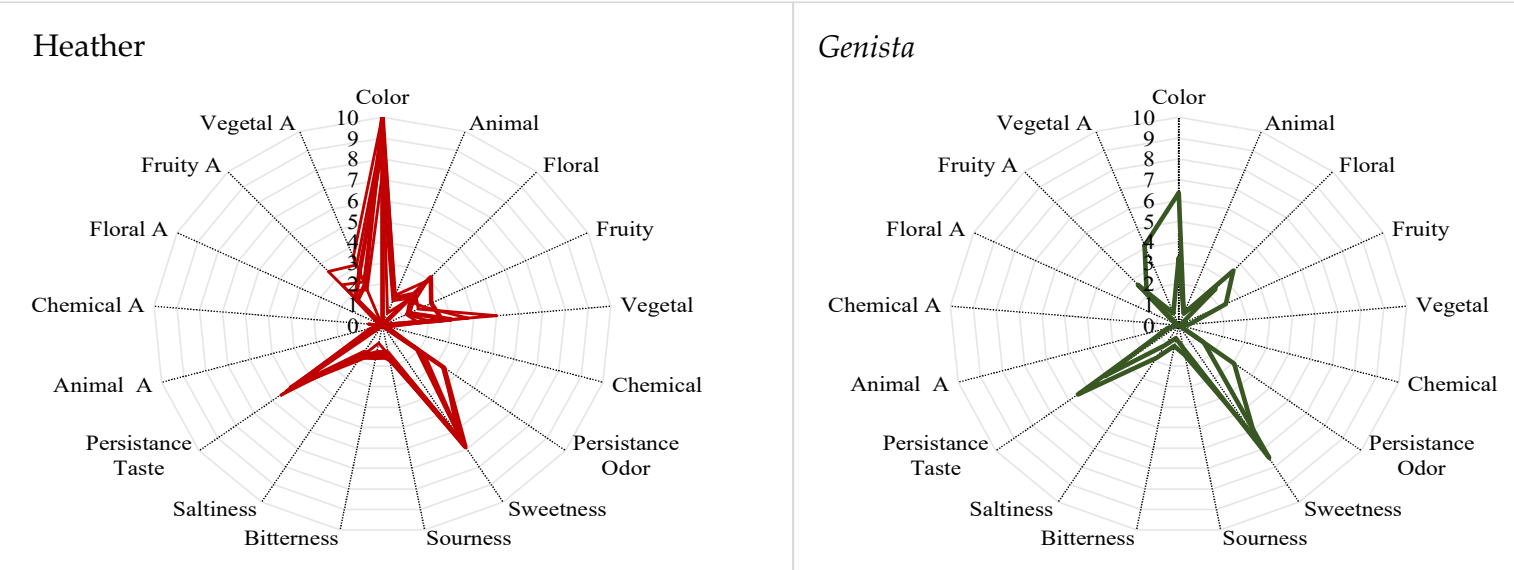

\section{Hedysarum}
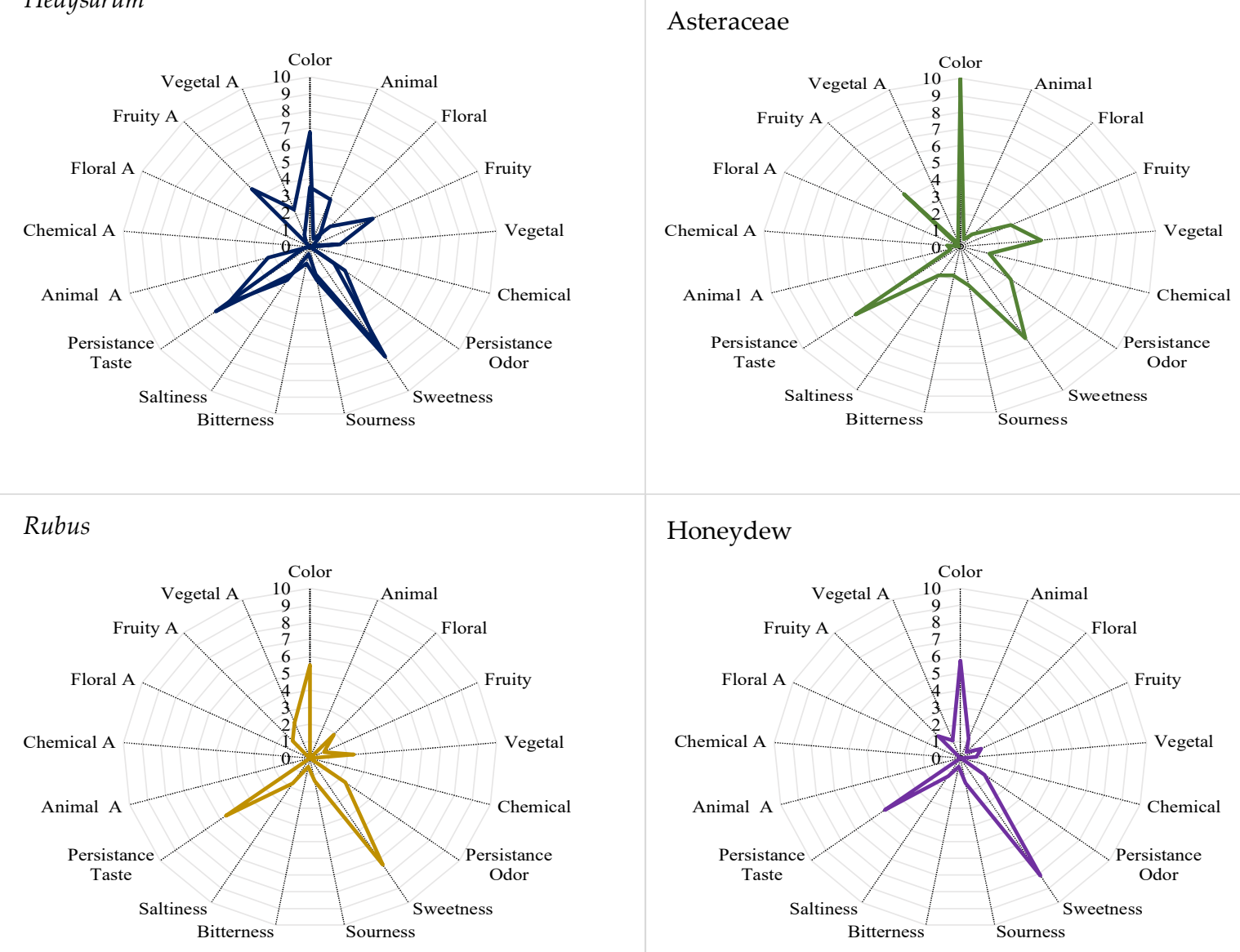

Honeydew

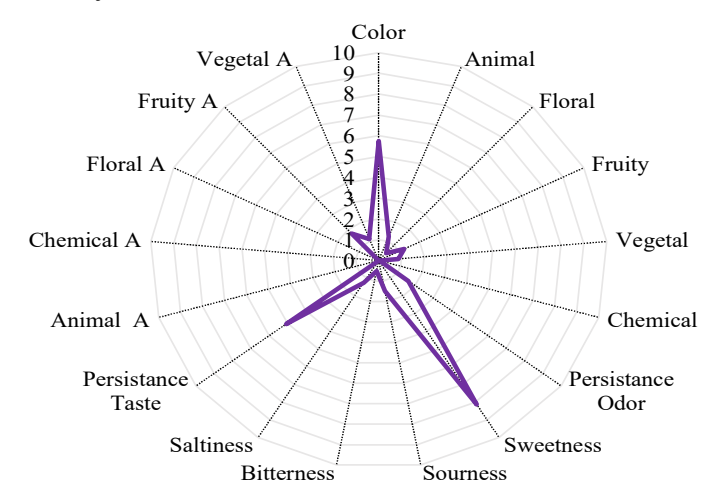

Figure 3. Chart diagrams for sensorial perceptions of monofloral honeys.

\section{Conclusions}

Honey samples collected from Babors Kabylia, which is an important biogeographical zone with great beekeeping potential, were analyzed to characterize the honey of this region using physico-chemical, melissopalynological and sensory parameters. The richness of the region in terms of melliferous plants has manifested through the production of a variety of monofloral honeys, including heather, Genista, sulla, Asteraceae and blackberry besides to the polyfloral honeys. Samples had a diverse sensory profile in terms of smell/flavor (vegetal, fruity and floral) highly appreciated by consumers. However, it is necessary to 
mention that some quality parameters related to hive management have been affected. It is therefore recommended to enhance knowledge on beekeeping management and to promote professional training for beekeepers to better manage the hive and improve both the quality and quantity of honey.

Author Contributions: Conceptualization, A.G. and F.B.; methodology, A.G., M.S.R.-F. and O.E.; formal analysis, A.G. and R.N.; data curation, M.S.R.-F. and O.E.; writing - original draft preparation, A.G. and L.H.; writing - review and editing, M.C.S.; supervision, F.B. All authors have read and agreed to the published version of the manuscript.

Funding: This research received no external funding.

Informed Consent Statement: Informed consent was obtained from all subjects involved in the study.

Acknowledgments: The authors express their gratitude to the beekeepers of the region. They would also like to thank the staff of the Apiculture Laboratory of the Animal Production Research Division of the National Institute for Agronomic Research-Algeria (INRAA) for their collaboration.

Conflicts of Interest: The authors declare no conflict of interest.

\section{References}

1. Hussein, M.H. A review of beekeeping in Arab countries. Bee World 2000, 81, 56-71. [CrossRef]

2. Boutabia, L.; Telailia, S.; Chefrour, A. Spectre pollinique de miels d'abeille (Apis mellifera L.) de la région d'El Tarf (Nord-Est algérien). Livest. Res. Rural. Dev. 2016, 28,1-8.

3. Véla, E.; Benhouhou, S. Évaluation d'un nouveau point chaud de biodiversité végétale dans le Bassin méditerranéen (Afrique du Nord). Comptes Rendus Biol. 2007, 330, 589-605. [CrossRef]

4. Ouchemoukh, S.; Louaileche, H.; Schweitzer, P. Physicochemical characteristics and pollen spectrum of some Algerian honeys. Food Control 2007, 18, 52-58. [CrossRef]

5. Haderbache, L.; Mouna, B.; Arezki, M. Ziziphus lotus and Euphorbia bupleuroides Algerian honeys. World Appl. Sci. J. 2013, 24, 1536-1543.

6. Otmani, I.; Abdennour, C.; Dridi, A.; Kahalerras, L.; Salem, A.H. Characteristics of the bitter and sweet honey from Algeria Mediterranean coast. Vet. World 2019, 12, 551-557. [CrossRef]

7. Homrani, M.; Escuredo, O.; Rodríguez-Flores, M.S.; Fatiha, D.; Mohammed, B.; Homrani, A.; Seijo, M.C. Botanical Origin, Pollen Profile, and Physicochemical Properties of Algerian Honey from Different Bioclimatic Areas. Foods 2020, 9, 938. [CrossRef] [PubMed]

8. Tomczyk, M.; Tarapatskyy, M.; Dżugan, M. The influence of geographical origin on honey composition studied by Polish and Slovak honeys. Cze. J. Food Sci. 2019, 37, 232-238. [CrossRef]

9. di Marco, G.; Manfredini, A.; Leonardi, D.; Canuti, L.; Impei, S.; Gismondi, A.; Canini, A. Geographical, botanical and chemical profile of monofloral Italian honeys as food quality guarantee and territory brand. Plant Biosyst. Int. J. Deal. All Asp. Plant Biol. 2017, 151, 450-463. [CrossRef]

10. Gharzouli, R. Flore et Végétation de la Kabylie des Babors Etude Floristique et Phytosociologique des Groupements Forestiers et Post-Forestier des Djbels Takoucht, Adrar Ou-Mellal, Tababort et Babor. Ph.D. Thesis, Ferhat Abbas University, Sétif, Algeria, 2007.

11. Rana, S.; Mishra, M.; Yadav, D.; Subramani, S.K.; Katare, C.; Prasad, G. Medicinal uses of honey: A review on its benefits to human health. Prog. Nutr. 2018, 20, 5-14.

12. Marcazzan, G.L.; Caretta, C.M.; Marchese, C.M.; Piana, M.L. A review of methods for honey sensory analysis. J. Apic. Res. 2018, 57, 75-87. [CrossRef]

13. Louveaux, J.; Maurizio, A.; Vorwohl, G. Methods of Melissopalynology. Bee World 1978, 59, 139-157. [CrossRef]

14. Bogdanov, S.; Martin, P.; Lüllmann, C. Harmonized methods of the European honey commission. International Honey Commission. Apidologie 1997, 1-59.

15. Singleton, V.L.; Rossi, J.A. Colorimetry of total phenolics with phosphomolybdic-phosphotungstic acid reagents. Am. J. Enol. Vitic. 1965, 16, 144-158.

16. Grand, A.A.; Vennat, B.; Pourrat, A.; Legret, P. Standardization of propolis extract and identification of principal constituents. J. Pharm. Belg. 1994, 49, 462-468.

17. Caroli, S.; Forte, G.; Iamiceli, A.L.; Galoppi, B. Determination of essential and potentially toxic trace elements in honey by inductively coupled plasma-based techniques. Talanta 1999, 50, 327-336. [CrossRef]

18. The Council of the European Union. Council Directive 2001/110/EC of 20 December 2001 relating to honey. Off. J. Eur. Communities 2002, L10, 47-52.

19. Karabagias, I.K.; Badeka, A.V.; Kontakos, S.; Karabournioti, S.; Kontominas, M.G. Botanical discrimination of Greek unifloral honeys with physico-chemical and chemometric analyses. Food Chem. 2014, 165, 181-190. [CrossRef]

20. Escuredo, O.; Míguez, M.; González, M.F.; Seijo, M.C. Nutritional value and antioxidant activity of honeys produced in a European Atlantic area. Food Chem. 2013, 138, 851-856. [CrossRef] 
21. Bilandžić, N.; Gajger, I.T.; Kosanovi'c, M.; Calopek, B.; Sedak, M.; Kolanovi 'c, B.S.; Varenina, I.; Luburi'c, D.B.; Varga, I.; Đoki'c, M. Essential and toxic element concentrations in monofloral honeys from southern Croatia. Food Chem. 2017, 234, $245-253$. [CrossRef]

22. Tafinine, Z.M.; Ouchemoukh, S.; Tamendjari, A. Antioxidant activity of some Algerian honey and propolis. Ind. Crops Prod. 2016, 88, 85-90. [CrossRef]

23. Dahmani, K.; Houdeib, J.B.; Zouambi, A.; Bendeddouche, B.; Fernández-Muiño, M.; Osés, S.M.; Sancho, M.T. Quality Attributes of Local and Imported Honeys Commercialized in Algeria. J. Apic. Sci. 2020, 1, 251-262. [CrossRef]

24. di Marco, G.; Gismondi, A.; Panzanella, L.; Canuti, L.; Impei, S.; Leonardi, D.; Canini, A. Botanical influence on phenolic profile and antioxidant level of Italian honeys. J. Food Sci. Technol. 2018, 55, 4042-4050. [CrossRef] [PubMed]

25. Bouyahya, A.; Abrini, J.; Touys, A.E.; Lagrouh, F.; Dakka, N.; Bakri, Y. Analyse phytochimique et évaluation de l'activité antioxydante des échantillons du miel marocain. Phytothérapie 2018, 16, S220-S224. [CrossRef]

26. Lachman, J.; Hejtmankova, A.; Sýkora, J.; Karban, J.; Orsak, M.; Rygerova, B. Contents of major phenolic and flavonoid antioxidants in selected Czech honey. Czech. J. Food Sci. 2010, 28, 412-426. [CrossRef]

27. Dong, R.; Zheng, Y.N.; Xu, B.J. Phenolic Profiles and Antioxidant Capacities of Chinese Unifloral Honeys from Different Botanical and Geographical Sources. Food Bioprocess Technol. 2013, 6, 762-770. [CrossRef]

28. Cheung, Y.; Meenu, M.; Yu, X.; Xu, B. Phenolic acids and flavonoids profiles of commercial honey from different floral sources and geographic sources. Int. J. Food Prop. 2019, 22, 290-308. [CrossRef]

29. Haouam, L.; Tahar, A.; Dailly, H.; Lahrichi, A.; Chaqroune, A.; Abdennour, C. Physicochemical properties and major elements contents of Algerian honeys from semi-arid regions. Emir. J. Food Agric. 2016, 28, 107-115. [CrossRef]

30. Tafinine, Z.M.; Ouchemoukh, S.; Bachir Bey, M.; Louaileche, H.; Tamendjari, A. Effect of storage on hydroxymethylfurfural (HMF) and color of some Algerian honey. Int. Food Res. J. 2018, 25, 1044-1050.

31. Haouam, L.; Dailly, H.; Bruneau, E.; Tahar, A. The quality of honeys influenced by the traditional heating method. J. Microbiol. Biotechnol. Food Sci. 2019, 8, 1276-1280.

32. Flores, M.S.R.; Escuredo, O.; Seijo, M.C. Assessment of physicochemical and antioxidant characteristics of Quercus pyrenaica honeydew honeys. Food Chem. 2015, 166, 101-106. [CrossRef] [PubMed]

33. Ouchemoukh, S.; Ouchemoukh, N.A.; Romero, M.G.; Aboud, F.; Giuseppe, A.; Gutierrez, A.F.; Carretero, A.S. Characterisation of phenolic compounds in Algerian honeys by RP-HPLC coupled to electrospray time-of-flight mass spectrometry. LWT Food Sci. Technol. 2017, 85, 460-469. [CrossRef]

34. Zerrouk, S.; Seijo, M.C.; Boughediri, L.; Escuredo, O.; Rodríguez-Flores, M.S. Palynological characterisation of Algerian honeys according to their geographical and botanical origin. Grana 2014, 53, 147-158. [CrossRef]

35. Oddo, L.P.P.; Piana, L.; Bogdanov, S.; Bentabol, A.; Gotsiou, P.; Kerkvliet, J.; Martin, P.; Morlot, M.; Ortiz Valbuena, A.; Ruoff, K.; et al. Botanical species giving unifloral honey in Europe. Apidologie 2004, 35, S82-S93. [CrossRef]

36. Bonvehi, J.S.; Manzanares, A.B.; Vilar, J.M.S. Quality evaluation of broom honey (Spartocytisus supranubius L.) produced in Tenerife (The Canary Islands). J. Sci. Food Agric. 2004, 84, 1097-1104. [CrossRef]

37. Galloni, M.; Cristofolini, G. Floral rewards and pollination in Cytiseae (Fabaceae). Plant Syst. Evol. 2003, 238, 127-137. [CrossRef]

38. Dimou, M.; Thrasyvoulou, A. Pollen analysis of honeybee rectum as a method to record the bee pollen flora of an area. Apidologie 2009, 40, 124-133. [CrossRef]

39. Berrekia, R.A.; Abdelguerfi, A.; Bounaga, N.; Guittonneau, G.G. Répartition des espèces spontanées du genre Hedysarum selon certains facteurs du milieu en Algérie. Fourrages 1991, 126, 187-207.

40. Chefrour, E.; Draiaia, R.; Tahar, A.; Kaki, Y.A.; Bennadja, S.; Battesti, M.J. Physicochemical characteristics and pollen spectrum of some north-east Algerian honeys. Afr. J. Food Agric. Nutr. Dev. 2009, 9, 1276-1293. [CrossRef]

41. Makhloufi, C.; Kerkvliet, J.; Schweitzer, P. Characterisation of some monofloral Algerian honeys by pollen analysis. Grana 2015, 54, 156-166. [CrossRef]

42. Nair, S.; Meddah, B.; Aoues, A. Melissopalynological Characterization of North Algerian Honeys. Foods 2013, 2, 83-89. [CrossRef] [PubMed]

43. Hamel, T.; Boulemtafes, A. Plants foraged by bees in the Edough peninsula (Northeast Algeria). Livest. Res. Rural Dev. 2017, 29, $1-13$.

44. Hamel, T.; Bellili, M.; Hamza, A.M.; Boulemtafes, A. Nouvelle contribution à l'étude de la flore mellifère et caractérisation pollinique de miels de la Numidie (Nord-Est algérien). Livest. Res. Rural Dev. 2019, 31, 1-24.

45. Escuredo, O.; Silva, L.R.; Valentão, P.; Seijo, M.C.; Andrade, P.B. Assessing Rubus honey value: Pollen and phenolic compounds content and antibacterial capacity. Food Chem. 2012, 130, 671-678. [CrossRef]

46. Piana, M.L.; Oddo, L.P.; Bentabol, A.; Bruneau, E.; Bogdanov, S.; Declerck, C.G. Sensory analysis applied to honey: State of the art. Apidologie 2004, 35, S26-S37. [CrossRef]

47. Araujo, D.; Cacho, P.R.P.; Serrano, S.; Palomares, R.D.; Soldevilla, H.G. Sensory Profile and Physico-Chemical Properties of Artisanal Honey from Zulia, Venezuela. Foods 2020, 9, 339. [CrossRef]

48. Flores, M.S.R.; Falcão, S.I.; Escuredo, O.; Seijo, M.C.; Vilas-Boas, M. Description of the volatile fraction of Erica honey from the northwest of the Iberian Peninsula. Food Chem. 2021, 336, 127758. [CrossRef]

49. Floris, I.; Satta, A.; Ruiu, L. Honeys of Sardinia (Italy). J. Apic. Res. 2007, 46, 198-209. [CrossRef] 